\title{
UMA VISÃO GERAL SOBRE A INTERNET DAS COISAS
}

\author{
Gustavo Marin Suppi ${ }^{1}$ \\ Márcio José Sembay ${ }^{2}$ \\ Igor Muzeka ${ }^{3}$ \\ Ingrid Solange Sepúlveda Muñoz ${ }^{4}$
}

Resumo: No decorrer dos anos, a tecnologia computacional tem evoluído, com os dispositivos móveis abriu um imenso leque de possibilidades de sistemas que visam facilitar a vida de toda a sociedade. Na Internet das Coisas, a conexão não se limita a esses dispositivos, mas a qualquer objeto no ambiente, desde torneiras até sinaleiras, onde formam uma estrutura de rede guiada por troca de informações, onde sensores captam informações do meio e enviam para dispositivos que as processam. Por meio de uma revisão de literatura, o objetivo foi coletar dados sobre essa nova infraestrutura, proporcionando ao leitor uma visão geral, expondo os principais pontos mencionados pelos autores dos artigos pesquisados. Concluiu-se que o objetivo da Internet das Coisas é de fato revolucionar o meio de como usamos a internet, desde a conectividade até a distribuição da informação, porém, para tal, será necessário fortes estudos em relação a segurança das informações obtidas dos usuários.

Palavras-chave: loT; Revolução tecnológica; Computação ubíqua.

\footnotetext{
1 Ciência da Computação, Centro Universitário Unifacvest, Brasil. E-mail: gustavomarinsuppi@gmail.com.

2 Ciência da Computação, Centro Universitário Unifacvest, Brasil. E-mail: igormzk21@gmail.com.

${ }^{3}$ Ciência da Computação, Centro Universitário Unifacvest, Brasil. E-mail: m_sembay@yahoo.com.br.

${ }^{4}$ Ciência da Computação, Centro Universitário Unifacvest, Brasil. E-mail: professoraingrid2009@hotmail.com.
} 